\title{
Learning as You Journey: Anishinaabe Perception of Social- ecological Environments and Adaptive Learning
}

\author{
$\underline{\text { Iain Davidson-Hunt and Fikret Berkes }}$
}

\begin{abstract}
This paper explores the linkages between social-ecological resilience and adaptive learning. We refer to adaptive learning as a method to capture the two-way relationship between people and their socialecological environment. In this paper, we focus on traditional ecological knowledge. Research was undertaken with the Anishinaabe people of Iskatewizaagegan No. 39 Independent First Nation, in northwestern Ontario, Canada. The research was carried out over two field seasons, with verification workshops following each field season. The methodology was based on site visits and transects determined by the elders as appropriate to answer a specific question, find specific plants, or locate plant communities. During site visits and transect walks, research themes such as plant nomenclature, plant use, habitat descriptions, biogeophysical landscape vocabulary, and place names were discussed. Working with elders allowed us to record a rich set of vocabulary to describe the spatial characteristics of the biogeophysical landscape. However, elders also directed our attention to places they knew through personal experiences and journeys and remembered from stories and collective history. We documented elders' perceptions of the temporal dynamics of the landscape through discussion of disturbance events and cycles. Again, elders drew our attention to the ways in which time was marked by cultural references to seasons and moons. The social memory of landscape dynamics was documented as a combination of biogeophysical structures and processes, along with the stories by which Iskatewizaagegan people wrote their histories upon the land. Adaptive learning for social-ecological resilience, as suggested by this research, requires maintaining the web of relationships of people and places. Such relationships allow social memory to frame creativity, while allowing knowledge to evolve in the face of change. Social memory does not actually evolve directly out of ecosystem dynamics. Rather, social memory both frames creativity within, and emerges from, a dynamic social-ecological environment.
\end{abstract}

\section{INTRODUCTION}

Sustainability of linked systems of humans and nature depends, in part, on the ability to deal with change. Much recent work has focused on these socialecological systems (SESs), and their capacity for learning and adaptation to deal with change (Gunderson and Holling 2002, Walker et al. 2002, Folke et al. 2003). But what is "learning"? Kai Lee's (1993:8) concept of "social learning" is a combination of adaptive management and political change (or bounded conflict). Adaptive management, treating resource management policies as experiments, provides the "compass" for setting course towards sustainability; bounded conflict, necessary to detect error and make corrections, provides the "gyroscope" for keeping course through turbulent pathways. Lee (1993:160) indicates that "social learning occurs through individual careers," consistent with the analysis of Westley (2002), who illustrates adaptive management by tracing the career of an "adaptive manager" who learned from mistakes and successes in both science and the political arena. Are there other dimensions of learning?

Folke et al. (2003) propose four principles for building adaptive capacity in SESs: (1) learning to live with change and uncertainty, (2) nurturing diversity for reorganization and renewal, (3) combining different types of knowledge for learning, and (4) creating opportunity for self-organization. Not only does learning comes up in the first and the third principles, but it is also central to the second, which is about social and ecological memory needed for reorganization and renewal. Folke et al. (2003) suggest that human actions framed by a dynamic and diverse social memory, in tune with ecosystem dynamics, have the potential to build adaptive capacity. They discuss 
both individual learning and institutional learning; however, they stop short of analyzing institutional learning. Nor do they discuss which processes may allow social memory to become dynamic, in tune with ecosystem dynamics.

The present paper addresses these challenges, and builds on Folke et al. (2003) and Berkes et al. (2003), to explore the linkages between learning processes at the individual and institutional levels and the way they interact with ecosystem dynamics. We refer to "adaptive learning" as a way of capturing the feedback component of learning explicit in Lee (1993) and Folke et al. (2003). Rather than dealing with learning as a purely individual or a collective phenomenon, we situate learning within the social-ecological system and consider it as a systems issue. Adaptive learning is treated as a way to build knowledge. In the indigenous peoples case study that we discuss in this paper, the kind of knowledge on which we focus is "traditional ecological knowledge," defined as a cumulative body of knowledge and beliefs, evolving by adaptive processes, and handed down through generations by cultural transmission (Berkes 1999:8).

This knowledge is remembered through "social memory," which is the long-term communal understanding of the dynamics of environmental change, and the transmission of the pertinent experience (McIntosh 2000:24). It captures the experience of change and successful adaptations. Embedded in values, social memory is actualized through community debate and decision-making processes into appropriate strategies for dealing with ongoing change (McIntosh 2000). Social memory describes how an individual thought, emerging out of a specific experience, can become part of the collective knowledge of a group. Social memory frames individual practice and creativity, and in turn is changed by individual practice and creativity. How does this occur? The adaptive learning model posits that memory (perception, cognitive knowledge, technology, institutions and worldview) is drawn upon by humans in the practice of daily life. It is this collective set of memories that allows the individual to deal with routine events and to respond creatively to novel events. Thus, social memory is the collective creative palette of a society upon which individuals draw to be competent members of a society. It is also the source of creativity and adaptation. But how can individual creativity, which emerges in response to a change in the social-ecological system, lead to change in social memory? We suggest that this requires a focus on what might be called institutions of knowledge.

We use the term "institutions" to mean the set of formal and informal rules actually used, rules-in-use (Ostrom 1990, Berkes et al. 2003:12). "Institutions of knowledge" are that subset of institutions which frames the processes of remembering, creativity, and learning. Framing these processes requires institutions that provide rules and values about remembering, creativity, and learning. This is part of the major resilience research area identified by Walker et al. (2002): "The rules that govern SES dynamics are not fixed. They evolve over time in response to both biophysical and social changes. Understanding how they evolve is crucial...." How are memories learned and transmitted? How does individual creativity lead to authoritative and legitimate social memory?

Adaptive learning provides a model to explore how individual creativity, social memory, and institutions of knowledge are interconnected. How learning leads to building adaptive capacity for increasing the "resilience" of social-ecological systems (Walker et al. 2002) is the question explored in this paper. We want to learn how institutions of knowledge may allow memory to emerge out of the dynamics of socialecological environments. These questions were explored in collaboration with indigenous philosophers who emphasize a holistic environment in which individuals are situated.

We provide the context of the research in the sections on study area and people, and research methodology. Next, we turn to a version of an adaptive learning model based upon Anishinaabe philosophy. This leads into our exploration of Anishinaabe perception of social-ecological environments through three sections in which we cover spatial perception, temporal perception, and perception and memory. First, we address the topic of spatial perception by examining perception of the biophysical landscape, and then incorporating social and cultural elements of perception, leading to cultural landscapes. Second, we discuss temporal perception through an examination of the Anishinaabe conceptualization of disturbance cycles. Again, we introduce social and cultural elements, leading to an understanding of Anishinaabe perception of cultural landscape dynamics.

Third, we address the linkages between perception and memory, "learning as you journey," and how people remember from places and journeys. We use the term 
"journey," not in the sense of passing through, but in the sense of traveling and re-traveling in an area, such that an intimate relationship with the land is developed. The term "travel" refers to the physical movement of a person from one place to another. In the final section, we discuss how institutions of knowledge allow ecological perception to lead to changes in memory. We do this by exploring the interconnections among institutions of knowledge, memory, and perception of social-ecological environments. We find that resilience may not just be what we know, but how we go about knowing what we know, which allows institutions to become adaptive and social memory to evolve.

Fig. 1. Map of the Shoal Lake study area. Iskatewizaagegan No. 39 Independent First Nation is located on Shoal Lake, Ontario, Canada.

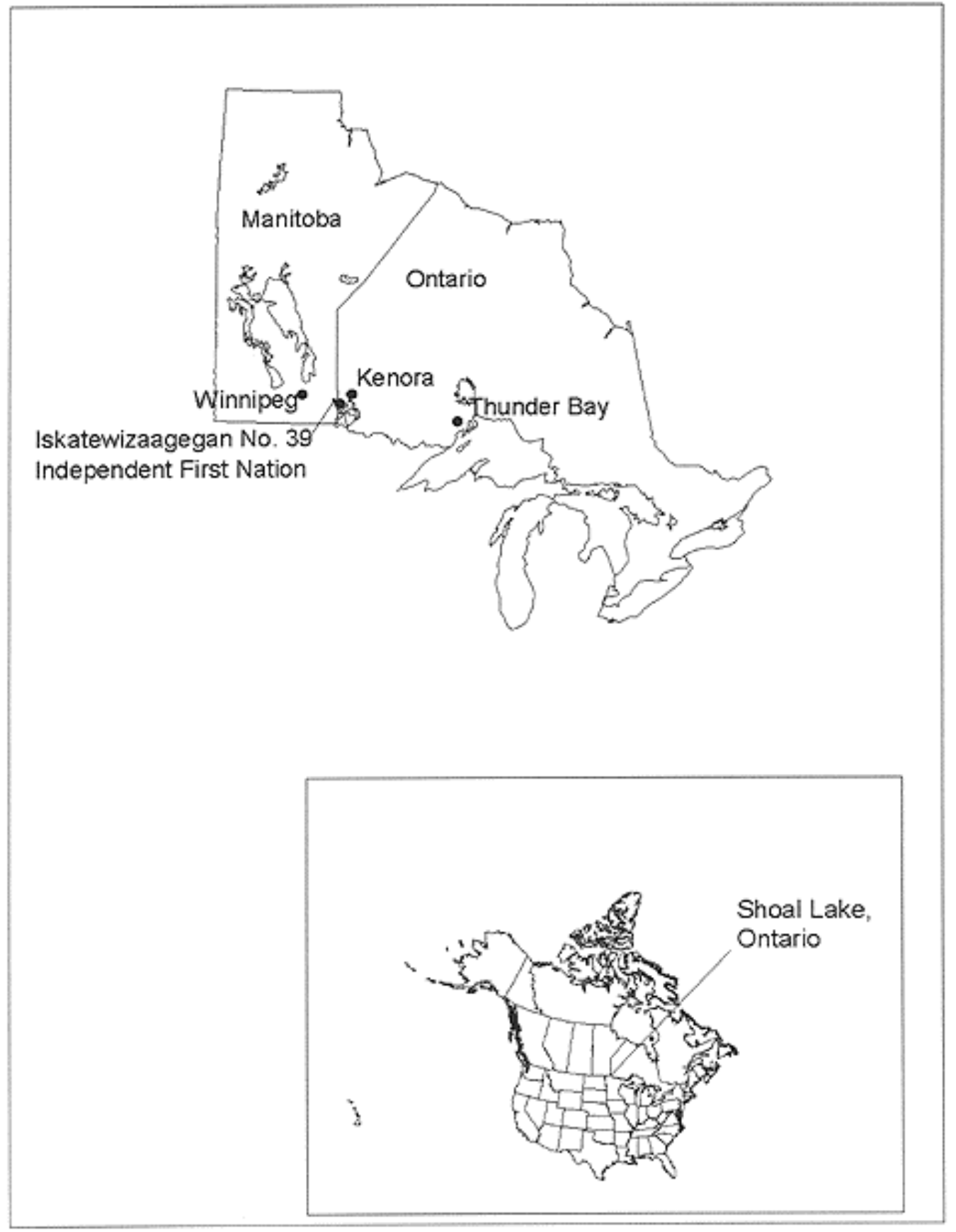




\section{STUDY AREA AND PEOPLE}

Research was undertaken with the Anishinaabe (also known as Ojibway, Ojibwa, Saulteaux, Chippewa) people of Iskatewizaagegan No. 39 Independent First Nation (IIFN), located near the border of Ontario and Manitoba, Canada (Figure 1). IIFN is one of two First Nations with permanent communities on Shoal Lake, with a combined population of 530 on-reserve band members and some 300 members living off-reserve. In this research, we worked with a number of people from the community. Brennan Wapioke was the community researcher and translator for the project. Ella Dawn Green, Robin Greene, Walter Redsky, Jimmy Redsky, and the late Dan Green, elders of the community, assisted in our research.

Anishinaabe is an Algonquian language. Algonquian is one of the largest indigenous language groups in North America. In the written historical record, the presence of Anishinaabe people in the region dates back to the early 1600 s. They were important participants in the fur trade from the $16^{\text {th }}$ to $19^{\text {th }}$ centuries, and signed a treaty with the Government of Canada in 1873. They were very mobile people and moved with the seasons in a hunting, gathering, and horticultural economy. Land-based activities continue to be an important part of IIFN livelihood and identity.

The Shoal Lake region is described as part of the Boreal Forest and the Lake of the Woods ecoregion. The natural history of Shoal Lake is notable, as it brings together three great biomes: Prairie, Great Lakes-St. Lawrence Forest, and the Boreal Forest. This is partly a result of the geology of the region. The thin, acidic soils of the Precambrian Shield give way to the deeper and more basic soils of the Prairie Biome, as one moves in a southwesterly direction. The region has a mean summer temperature of $15^{\circ} \mathrm{C}$, and a mean winter temperature of $13^{\circ} \mathrm{C}$. Precipitation is evenly distributed throughout the year and is about $600 \mathrm{~mm}$.

This unique set of biophysical features allows for a biologically diverse mixture of vegetation. Tree species typical of the Great Lakes-St. Lawrence Forest co-exist with those of the Prairie Biome and the Boreal Forest. A rich mix of shrub and herbaceous species, extensive wetlands, treed bogs, and fens adds to the diversity of the flora. The fauna is likewise diverse and includes large mammals, such as ungulate species, small game species, fur mammals, waterfowl, and upland game birds. The Shoal Lake region is noted for its fish. This diversity of plants and animals has provided the people of IIFN with a wealth of resources for their livelihoods in the fur-trading era and the contemporary period.

Typical of many Canadian First Nations, the people of Shoal Lake have a mixed economy consisting of wage employment, transfer payments, and living off the land (Berkes et al. 1994). Although trapping has diminished, due to the collapse of the fur economy in the mid 1980s, most households on the reserve exhibit the lifestyle described in this paper. Only a few individuals, however, are considered to be experts in bush knowledge. A concern about diminished activity on the land, and subsequent loss of language and knowledge, was a primary reason cited by elders for why they agreed to participate in this study.

\section{RESEARCH METHODOLOGIES}

The research reported here was undertaken during two field seasons, May to October 2000, and July to October 2001. Verification workshops to confirm findings with the community were held in January 2001, and again between January and April 2002. The research was undertaken in cooperation with a community researcher, the Shoal Lake Resource Institute, elders, and the local government of IIFN.

The methodology was a combination of site visits to a place where community elders knew the plants, and transects determined by known travel routes. During these site visits and transect walks, research themes were used to generate conversations. Discussions of the major themes of plant nomenclature and plant uses occurred during site visits, while habitat descriptions, biophysical landscape nomenclature, and place names were discussed during both site visits and transect walks.

Plant vouchers were taken for species identification. Photographs, videos, GPS readings, and informal interviews were used to obtain specific information about plants. Photographs and videos, as well as with GPS readings, were taken of different types of habitat, biophysical landscapes, plants, and named locations. As new habitats, biophysical landscapes, plants, and named locations were encountered, an informal conversation would be initiated about those topics. Map interviews were held with elders about place names. These discussions often led to stories about places and the activities that used to occur in specific places. On a few occasions, such interviews led to new site visits. Essentially, the methodology could be 
summarized as one in which the researcher approaches a knowledgeable person and explains what he would like to learn. This person then structures the learning experience regarding the steps to be taken and the places that must be visited, so that learning may occur.

Table 1. A model of adaptive learning based upon Anishinaabe philosophy and institutions of knowledge.

$\begin{array}{lll}\text { Philosophical } & \text { Institution of } & \text { Teaching from Shoal Lake Elders } \\ \text { Principle } & \text { Knowledge } & \text { (Teaching represented by core statements) }\end{array}$

Knowledge Revelation

resides

in the land

Place-based

Holistic

Embedded Subjects

Knowledge is

progressively

Direct Coupling

revealed

through

experience

on the land
People are gifted for different things. Beings reveal knowledge to people through visions and dreams (Ella Dawn Greene).

When traveling, the person who knows the land the best always leads the way (Walter Redsky).

When I am healing a person, a plant will reveal itself in a dream and then I know I should use it for that person (Ella Dawn Green).

A powerful person has learned to show respect to other beings and has developed a finely tuned awareness of his land. Other beings begin to reveal themselves so he becomes a better hunter, fisherman, or healer (Robin Greene).

You should know where everything is on the land with which you are familiar. My father, in the middle of winter, could go to the exact place, thrust his hand through the snow and dig up the root he needed for healing (Walter Redsky).

Empirical

Observation

When you are on the land with someone, you should always be watching where you are and what the other person is doing (Walter Redsky).

Personal and

Collective

Ceremonies

Social Gatherings

You can do ceremonies by yourself or as part of a group. Ceremonies are necessary to show respect to others for what you are about to undertake (Robin Greene).

We used to always get together as a group in the summer to harvest fish, blueberries, and wild rice (Walter Redsky).

Self-awareness After harvesting a lot of something, like birch bark, you should go back and leave cloth and tobacco. Let the birch trees know that you respect them by giving them something for what you were given (Ella Dawn Green).

Mentoring The right way to be taught is not from a book. It is from your aunties, uncles, mom, dad, and other people who know the land (Jimmy Redsky).

Language Our language is very descriptive. It tells us things like how one thing might be related to another. Or the way that things look like on the land (Dan Green).

Narrative $\quad$ Our people never wrote anything down. We know our land and our history from the stories we tell (Jimmy Redsky).

\section{AN ADAPTIVE LEARNING MODEL}

In Table 1, we present a model of adaptive learning based on Anishinaabe philosophy. We propose that there are two basic philosophical premises relevant to a theory of adaptive learning. First, a society must have a principle that addresses where "truth" resides. Second, a society must have a process by which truth 
statements regarding reality may be constructed and modified (Borofsky 1987).

As we understand our Anishinaabe colleagues, they suggest that truth resides within the beings of the land itself. Institutions of knowledge, which we have characterized as revelation, place-based, holistic, and embedded subjects, provide the rules on the "nature" of truth. Truth cannot be discovered but is "revealed" as part of a person's development within a web of relationships of a place (Ingold 2000). There is no separation between society and individual, culture and nature, nor society and environment. Individuals move in and out of networks, operative for specific places, as they undertake their own projects. They become more competent as individuals as knowledge is revealed to them through their participation in life experiences and subject-to-subject relationships. This is quite different than a Cartesian perspective on "truth." In a Cartesian perspective, truth is to be discovered in mathematically described, universal, simplified, and subject-to-object relationships (Ingold 2000). However, many contemporary scientists differ from the Cartesian ideals; as one reviewer commented, the Anishinaabe view may have parallels to the dialectical thinking of such ecologists as Levin (1999).

The basis of how truth statements may evolve in Anishinaabe society is related to the perspective that knowledge is progressively revealed to individuals through their guided experience on the land. An individual is expected to learn through participation in experiences on the land under the guidance of a knowledgeable person, while also engaging in collective experiences. Again, institutions of knowledge such as direct coupling, experience on the land, self-awareness, mentoring, language, and narrative provide a set of rules by which perception of the environment develops within a social-ecological context. These institutions also allow for individual perception of changes in the land to lead to changes in individual behaviors and practices. Other members of Anishinaabe society will consider change suggested by a person who has followed the institutions of knowledge seriously. As truth is linked to knowledge of the land, then changes in truth statement are linked to changes in the land. Anishinaabe philosophy builds a direct link between the land and practice.

In order for this mechanism to work, there must be a basic perception of the spatial and temporal characteristics of the land. There must be a perception of structures, interrelationships, and processes that are occurring on the land so that change may be recognized and adaptive learning take place. However, some change is just cyclical. Therefore, there must also be the ability to distinguish between cyclical change and change that represents a need to adapt. Both types of knowledge must somehow be encoded in a form that can be taught to others. This can be ceremonial, embodied experience, songs, narratives, or many other forms (Table 1). In the next two sections, we present a simplified version of Anishinaabe landscape knowledge through an examination of spatial and temporal terminology for landscape structures, relationships, and dynamics. We then look at how memory (encoded perception) and institutions of knowledge interact to build adaptive capacity in Anishinaabe society.

\section{SPATIAL PERCEPTION OF THE LAND}

Ecological perception is usually considered to occur along two axes, spatial and temporal. Spatial perception relates to how patterns of things, such as resources, are distributed across the landscape. Ecological theory requires categories that can be used to describe spatial distribution, interrelationships, and properties at a specified scale (Levin 1999). Likewise, units can be created which describe distribution, interrelationships, and properties along a temporal axis. Such knowledge, we thought, would be a prerequisite for adaptive learning. Knowledge, for example, of where a plant is growing allows you to harvest that resource, as long as that plant community does not change. What do you do if a fire destroys that particular location of a plant community? We hypothesized that it would be necessary to perceive such categories so that a new resource harvest area might be found. A standard ethnobiological approach to this type of question is to look for terminology ("linguistic signifiers") of cognitive categories related to spatial and temporal patterns of the landscape (Berlin 1992).

This section presents the results of our exploration of these questions with our Anishinaabe colleagues. As we discuss, our Anishinaabe colleagues concurred that their language described the spatial and temporal patterning of the landscape. However, they insisted that knowledge of where a resource might be found also required an understanding of the social and cultural patterning of particular landscapes. 
Fig. 2. An idealized schematic of Anishinaabe biogeophysical knowledge. A sample of terms.

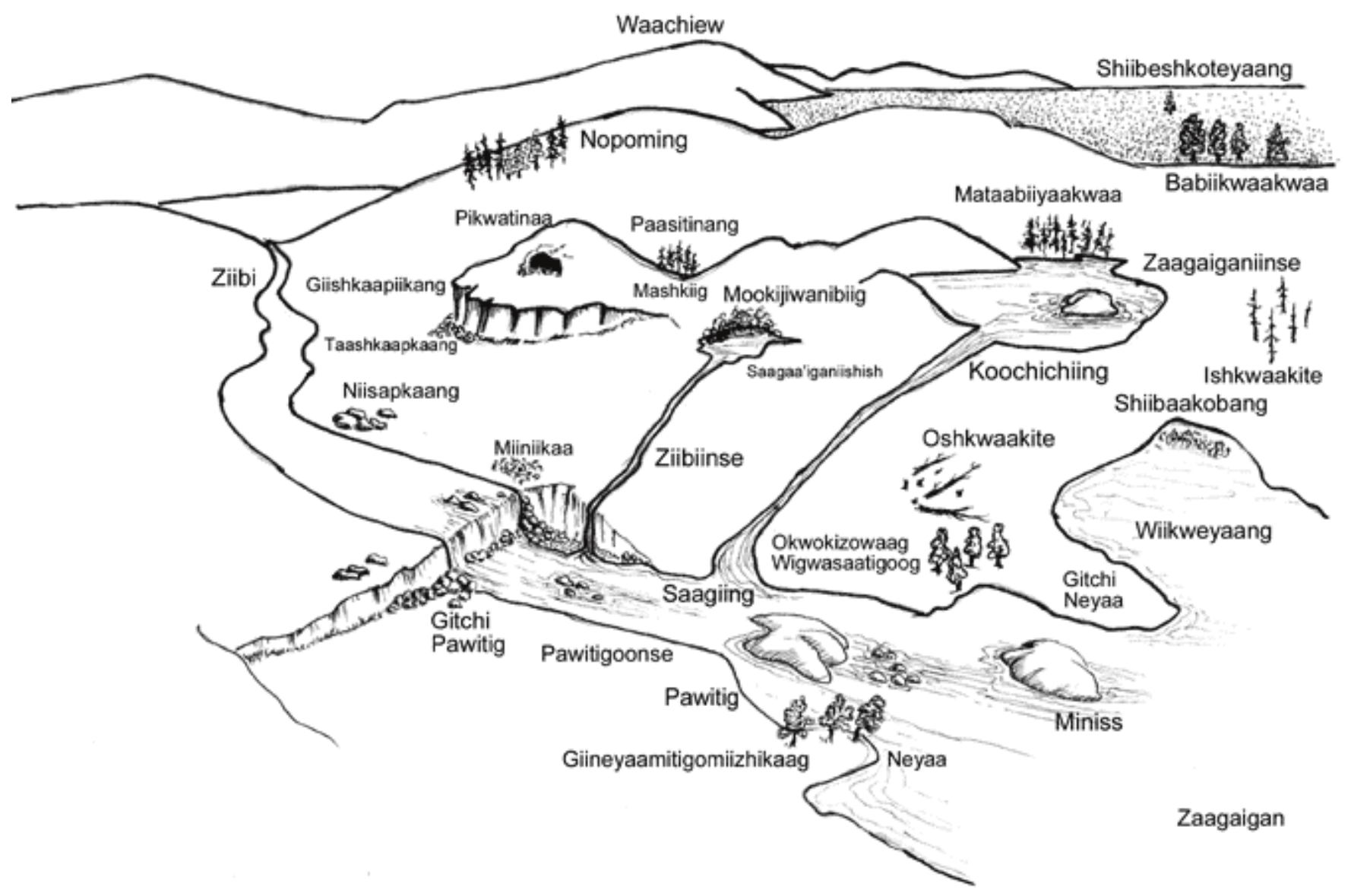

\section{Perception of biophysical landscapes}

Figures 2 and 3 demonstrate the complexity of our Anishinaabe colleagues' perception of the spatial patterns of the biophysical landscape. Appendix 1 provides a more exhaustive list of Anishinaabe landscape vocabulary. Obvious landscape features are perceived and named (e.g., lakes - zaagaigan, rivers ziibi, hills - pikwatinaa). More interesting is the evidence of relational concepts, such as river inlet koochichiing and river mouth - saagiing. Important functional features, such as a spring - mookijiwanibiig, and complex relational features, such as a rocky slope on the banks of a water body - niisapkaang, are also part of perception of landscape patterns. As well, the language provides evidence that relationships between physical features and biological structures are recognized. A point that contained a specific type of tree was described by combining the name of the physical feature with the vegetation that was growing there. For example, a bur oak point was referred to as giineyaamitigomiizhikaag, which would be directly translated as "there point bur oak place."

Landscape patterns that are made up of biological structures are also demonstrated in the language. Forest patches are denoted by the term okwokizowaag. Thus, a grove of birch trees is called okwokizowaag wigwasaatigoog. Another example is the use of the linguistic unit $-k w a a$, and variants, to describe patches of vegetation. A blueberry patch, for example, is denoted by the word miiniikaa which combines the word for blueberry with that of the descriptor for patch which provides the patterning of blueberries growing in a patch.

The Anishinaabe language suggests that the recognition of physical features, biological structures, 
and interrelationships would allow for the spatial patterning of the landscape into categories and subsequent functions. Our thinking led us to suggest that for our birch research, we could look for okwokizowaag wigwasaatigoog. This would be facilitated by our knowledge that okwokizowaag wigwasaatigoog was equivalent to vegetation-type V4 of the Ontario Ecological Land Classification (OELC) (Ontario Ministry of Natural Resources 1996, Sims et al. 1989). By looking for V4 ecosites (mapping scale of the OELC) in the Ontario Forest Research Inventory, we could locate our research sites. Our Anishinaabe colleague, Walter Redsky, did not concur. Walter perceived birch groves when encountered on the landscape. However, he did not organize his knowledge of the spatial distribution of birch patches as a map. He used a different system to construct a pattern of the distribution of birch within the landscape.

Fig. 3. English translation of Anishinaabe biogeophysical knowledge.

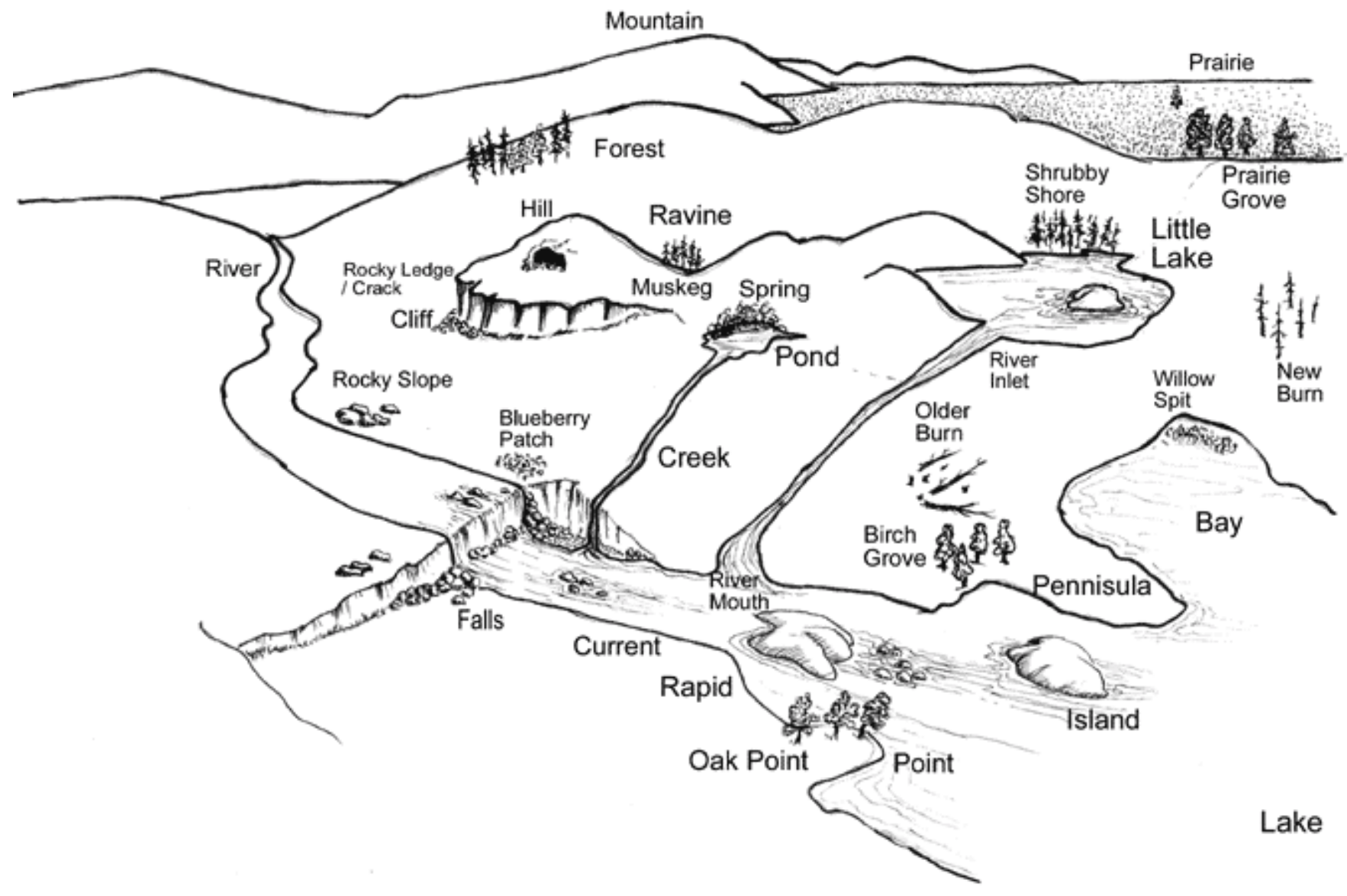

\section{Perception of cultural landscapes}

Jimmy Redsky, another Anishinaabe colleague, listened respectfully as we presented the results on Anishinaabe terms for ecological units and OELC equivalents. After a time, he suggested that we had not paid enough attention to the history of the land. Although he agreed with the linguistic description of the land we presented, it just did not seem complete.
He thought we should begin to consider how Anishinaabe people drew upon their history in order to begin to understand how they perceived the spatial patterns of the land.

One way to link the history of a people with their occupancy of a land is through place names. For people who do not use maps, place names provide a mental image of how a particular place within the 
landscape looks, how it is related to other places, what occurred at that place and/or what might be found at the place. For instance, Gitchinayaashing describes a big point, Aagimakobawatig a place where black ash grows beside a rapid, Gaanikooshkooshkaag Zaagaigan a lake where a specific type of plant grows,
Ogishkibwaakaaning where wild potatoes grew, Gitigaani Minis an island where gardening occurred, Animoshi Minis where the howling of dogs was said to have been heard in the past. Place names are the fixed nodes, reference points, upon which the creation of spatial patterning of the landscape is built.

Fig. 4. A schematic of an Anishinaabe perspective on forest disturbance cycles. Arrows represent the relative temporal scale of a cycle but not a temporal metric.
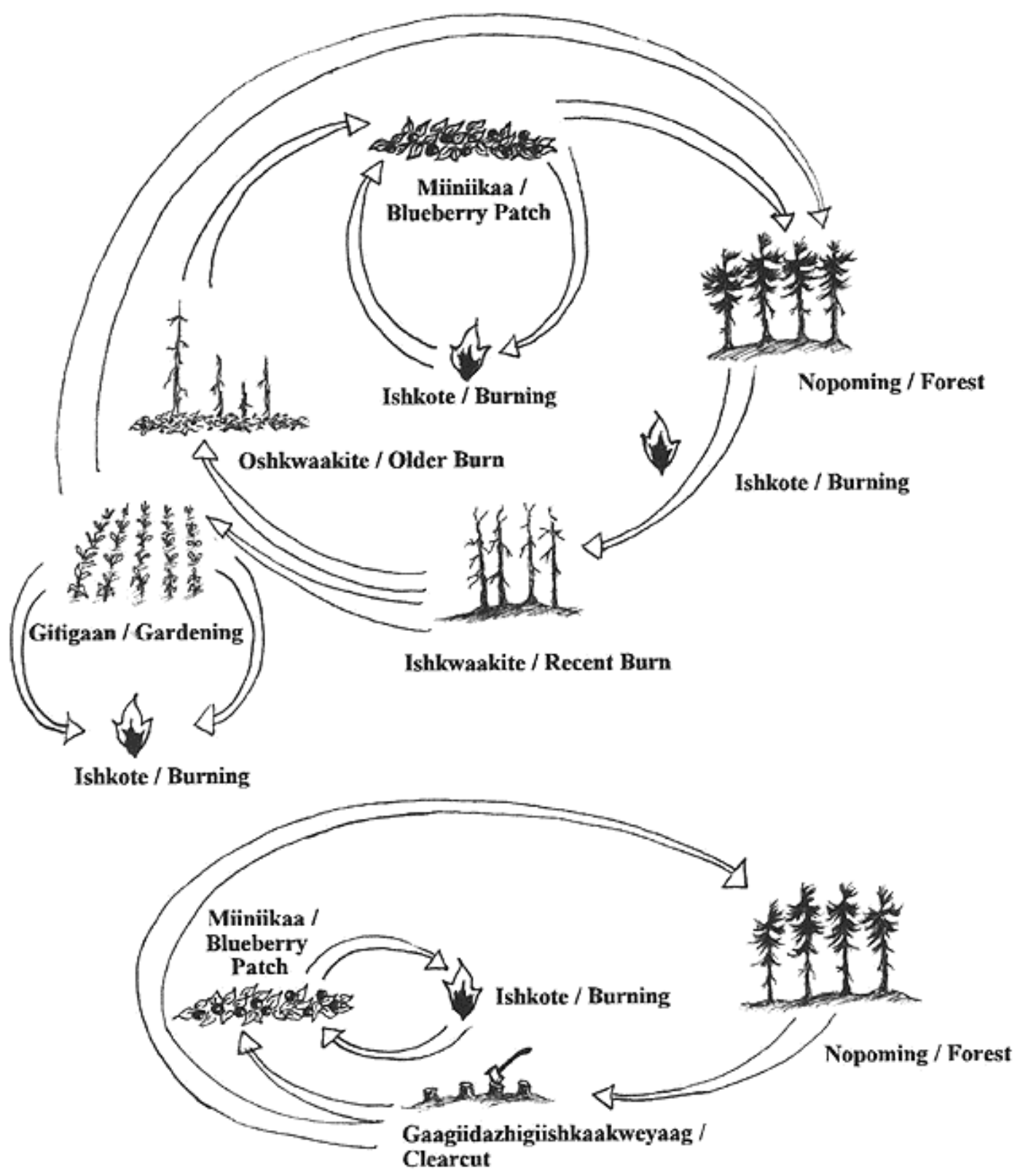

Place names did not just mark places, but brought together places in relation to each other linked by paths of travel. The Anishinaabe traveled using waterways, lakes, portages, and winter trails, pathways 
along which either a canoe or a dog team could pass. Trails link together different nodes. Places and trails provided the references for remembering the path of a journey from one place to another. The landscape, in this perspective, becomes a network of nodes and trails that orient a person in physical, social, and cultural space. Thus, spatial patterning does not exist independently of the journeyer nor does it exist until the journey occurs. As both the journeyer and journey are physical, social, and cultural in nature, the knowledge of the spatial pattern of a landscape requires access to these three axes. So Walter and Jimmy thought that maps and habitat categories were a rudimentary way to find where birch groves were located. Once they knew what we were looking for, they could get us to the place situated in physical, social, and cultural space and which would be appropriate for our task at hand.

\section{TEMPORAL PERCEPTION OF THE LAND}

Landscape patterning becomes increasingly complex as one adds temporal dynamics to the spatial distribution of plant communities and resources. We began our discussion with Anishinaabe colleagues through a process similar to that described above. We searched for linguistic markers of the temporal dynamics of the landscape. We thought the best way to generate such discussion would be to visit sites a given number of years following a disturbance. A primary post-disturbance activity, blueberry picking following fire and logging disturbances, was chosen to focus the discussion. We then asked our Anishinaabe colleagues for a word that they would use to describe such sites.

\section{Perception of disturbance dynamics}

During verification workshops, held in the fall and winter of 2001-2002, Ella Dawn Green and Walter Redsky were asked to construct a temporal forest cycle. The different names that were gathered during field research were put together into a diagram (Fig. 4 ), and the processes of forest changes were discussed. The cycle they constructed contained a number of different categories of forest following a disturbance event (ishkote) through to a mature forest (nopoming). A number of different categories are noted in Fig. 4.

Our Anishinaabe colleagues also noted different pathways that followed a disturbance event. Fire could be initiated by lightening or by a person. In Anishinaabe philosophy, both events require an agency but each event occurs due to the location of agency in different beings. In this perspective, the category of "wildfire" does not exist. In either case, disturbance could follow a pathway back to mature forest or could lead to an area cleared for a garden. The process of burning and planting eventually leads to an area that is free of roots and easily planted. Eventually, such sites would revert back to mature forest when abandoned. Another pathway that was described is that which follows logging disturbance. Robin Greene thought such sites would revert to mature forest. However, they are still waiting to assess the long-term outcome of this cycle as it is a relatively recent occurrence. Different categories and pathways produce sites for different activities and intensities of use. Some were useful for gardening, some for blueberry harvesting, and others for hunting moose.

The construction of such temporal cycles was a rewarding process for our participation in the research. However, our Anishinaabe colleagues again challenged our description of how they perceived temporal dynamics. Linguistic evidence that we collected did demonstrate that there is a perception of the temporal dynamics of landscapes. However, the cycles that our Anishinaabe colleagues felt were more important were marked by words that denoted an interconnected shift in the landscape and which brought together the biological, social, and cultural aspects into a dynamic cultural landscape.

\section{Perception of cultural landscape dynamics}

One activity that demonstrated the way in which perception of the dynamics of the cultural landscape was operating, was the harvesting of birch bark. Walter Redsky and Ella Dawn Green mentioned that this activity had to be done when the birch bark was ready to be peeled. The timing of the birch bark harvest did not correspond to the calendar, but to the development of the birch tree in a given year. There was a time in the early summer when the bark loosened from the tree and could be peeled. Before or after this time, the bark did not peel cleanly and ripped when harvested. This time corresponded to the time when raspberries ripened. Perception of temporal dynamics was linked to the awareness of changes that occur in the landscape and adjusting social and cultural activities appropriately. Such awareness was built through acute awareness of the land, experience on the land, and marked by different ways in the language.

One way in which temporal dynamics are marked in the language is in the concept of the six seasons that 
are considered to change on the basis of changes in the biogeophysical environment. Figure 5 outlines the cycle of the seasons that are denoted according to changes in the landscape. Tagwaagin, for instance, begins when the leaves turn color and fall from the trees. Tagwaagin turns into oshkibiboon, when all the leaves have fallen from the trees and the first snows are falling. Biboon turns to ziigwan when the ice on the lakes begins to melt and break up. Rather than sharp edges delineating seasons there are periods of transitions from one season to another. A season changes more quickly in a year when there are quick changes in the ambient environment. Periods of seasonal change are keenly observed and warrant frequent comment. Differences in how seasons are changing are measured against other years and provide a baseline for noting seasonal changes that are considered to be anomalies.

Fig. 5. Anishinaabe perspectives on temporal cycles. Seasons are related to changes in the biological environment, whereas lunar cycles provide a fixed metric.

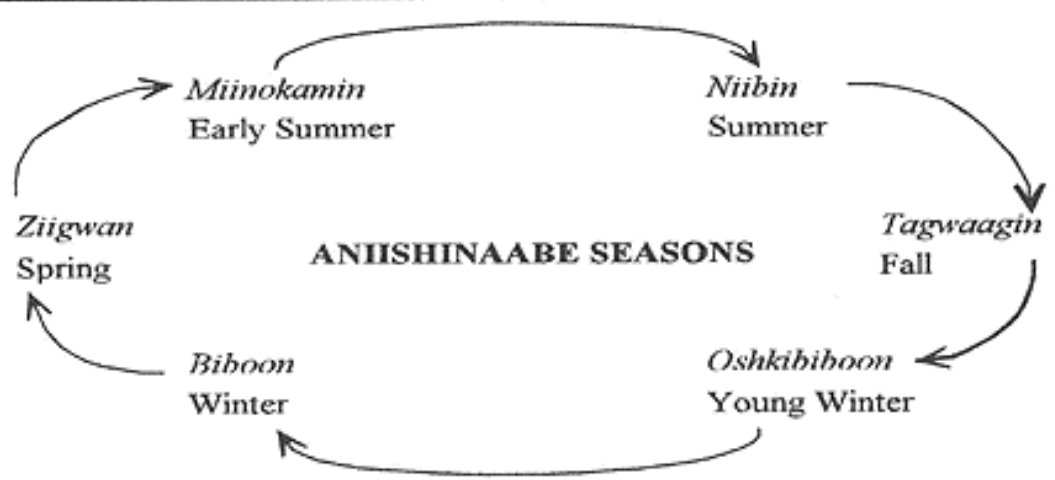

Miinikaa Giizis

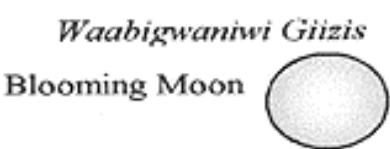

Zaagibagaawi Giizis

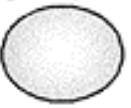

Budding Moon Maangwag Giizis<smiles>C1CCCCCCCC1</smiles>

Loon Moon

Aandegwag Giizis

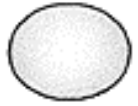

Crow Moon

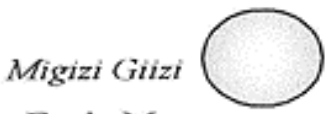

Eagle Moon

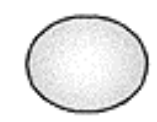

Berrying Moon

GICHI MANIDOO

GREAT CREATOR

Whitefish Spawing Moon

Majibiboone Giizis

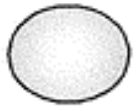

Leaves Falling Moon

Adikamegiwi Giizi

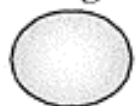

Manidon Giizis

Creator's Moon

Leaves Chaning Color Moon

Binaakwewi Giizis

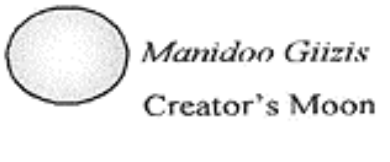

Old Winter Moon 
The yearly passage of time is also linked to changes in the activities that should be undertaken. Feasts are held during these periods of seasonal change and mark cultural activities. Such feasts teach that certain activities and behaviors are appropriate for different times of the yearly cycle. A person will hold a feast to respect the beings who made life possible during the season past and those who will make it so in the season to come. For instance, as ziigwan turns into miinokamin, a feast to celebrate the first fruits is held. This feast shows respect to the plant beings that share with the Anishinaabe during berry-picking season. Perception is not just created by noting changes in the biological environment, but also by the social and cultural activities that orient a person to the temporal dynamics of a cultural landscape.

Another system used by the Anishinaabe to mark the temporal dynamics of seasonal change was the moon cycle. This provided a more standardized way to note the passage of time during the year. Migizi giizis, translated as "bald eagle moon," marked the time when the bald eagles returned. Maangwag giizis denoted the time when loons returned and began to nest. Other moons, such as Miinikaa giizis - " blueberrying moon" and Manoominike giizis - "ricing moon," marked the time period when different livelihood activities were undertaken. Other names for the moons referred to the time when certain ceremonies were undertaken, such as Manitoo giizis, "Creator's moon." Similar to the concept of seasons, the moon cycle brought together the biological, social, and cultural aspects into a way to mark the temporal dynamics of the cultural landscape.

When we began to search for linguistic markers of temporal dynamics, we thought that the existence of such categories would help us understand Anishinaabe perception of temporal dynamics. Recognition of temporal dynamics was considered to be important to a theory of adaptive learning. People would need to be able to distinguish between the temporal patterns of cyclic change and change that required a change in social and cultural behavior. However, our Anishinaabe colleagues took a different approach to this question. There is the linguistic marking of different plant communities following disturbance. However, perception of temporal dynamics also emerges out of experience on the land that is biological, social, and cultural. Perception does not exist independently of the person, nor can it occur prior to a person's participation in an event; it is embedded in the temporal patterns that emerge from the biological, social, and cultural interconnections of a people and landscape.

\section{PERCEPTION AND MEMORY}

Remembering, for Anishinaabe people with whom we worked, begins with a person situated in a spatial and temporal context. This is different from a Cartesian perspective, in which one assumes that people are situated outside of a spatial and temporal context. Spatially, the Cartesian perspective is like the view from an airplane. Temporally, it can be considered as the perspective gained from a time series sequence of photos, where time can be compressed into the present. This view allows a person to distinguish replicating patterns of biogeophysical structures (landforms) established by biogeophysical processes. These replicating patterns can then be turned into categories of habitat types, so that some categories can be grouped, while others are differentiated. Temporal pathways can then be established for each category of habitat type. Habitats can then be related and mapped in Cartesian space, described by biological, geological, and physical structures and processes, and described by change over time. These spatial and temporal categories become containers for holding information, that can be mapped in Cartesian space and time. Memory becomes detached from a location in an environment to a category located outside the environment.

Anishinaabe ways of remembering are akin to the experience of journeying within the land, a journey that is situated in both space and time. The practices, moons, seasons, and ceremonies that mark the passing of diurnal, yearly, and life stages often structure the journey temporally. Spatially, the paths of travel link places that can be revealed and described as they are encountered. Places change in yearly and longer-term cycles. These changes are observed and remembered through frequent journeys. Places are known in relation to the paths of journey and reference points that orient a person within the land. Memory is embedded in the land and the people. The spatial and temporal locations of things can never be forgotten as long as the journeys continue.

This perspective on memory is reflected in the way in which Anishinaabe elders taught about plants and where to find them on the land. They did not prioritize categories of habitat so that the location of plants might be remembered; they described the location where they remembered having encountered a plant in 
the past. Such locations were described by recalling the journey along paths of travel and places that were encountered along that path. Stories about places turned locations into places of remembering and points of reference within the land. Anishinaabe ways of remembering brought to mind events that occurred in the past, stories, place names, physical features, and biological features, not just landforms.

Fig. 6. An idealized schematic of an Anishinaabe Cultural Landscape. Cultural landscapes are a mixture of biogeophysical, artifactual, and known (named or unnamed) features. A sample of terms.

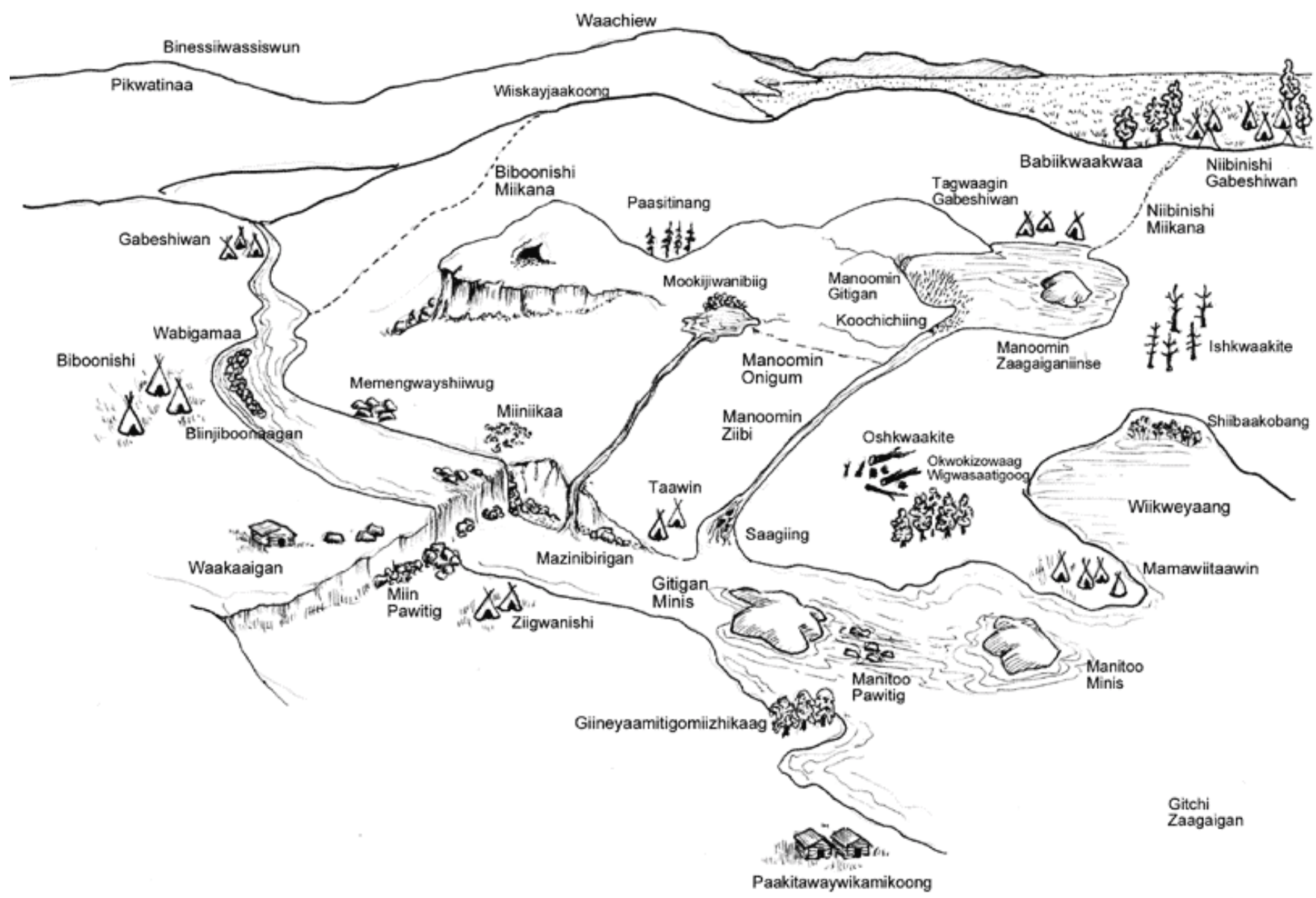

Figures 6 and 7 provide an idealized schematic of the way in which this perspective remembers the spatial and temporal dynamics of the land. Campgrounds, trails, portages, cabins, planting areas, cultivated fields, ricing lakes, hills, mountains, habitat patches, rapids, stony slopes, springs, "thunderbird nests," homes of the "little people" and many other biological, physical, and cultural features come together to form different places on the landscape. It is the spatial and temporal dynamics that create places, places that are remembered as they are encountered along the paths of remembering. The land, the people, and their histories become the interwoven social-ecological environment in which Anishinaabe people undertake daily practices, learn, and create new memories.

\section{ADAPTIVE LEARNING BY ISKATEWIZAAGEGAN PEOPLE}

Adaptive learning in the Anishinaabe framework emerges out of a learning environment that is spatially and temporally patterned by physical, biological, social, and cultural structures and processes. In the examples provided below, we attempt to illustrate that adaptive learning does not occur in response to an environment, but as part of an environment (details in Davidson-Hunt (2003)). 
Fig. 7. English translation of an Anishinaabe cultural landscape.

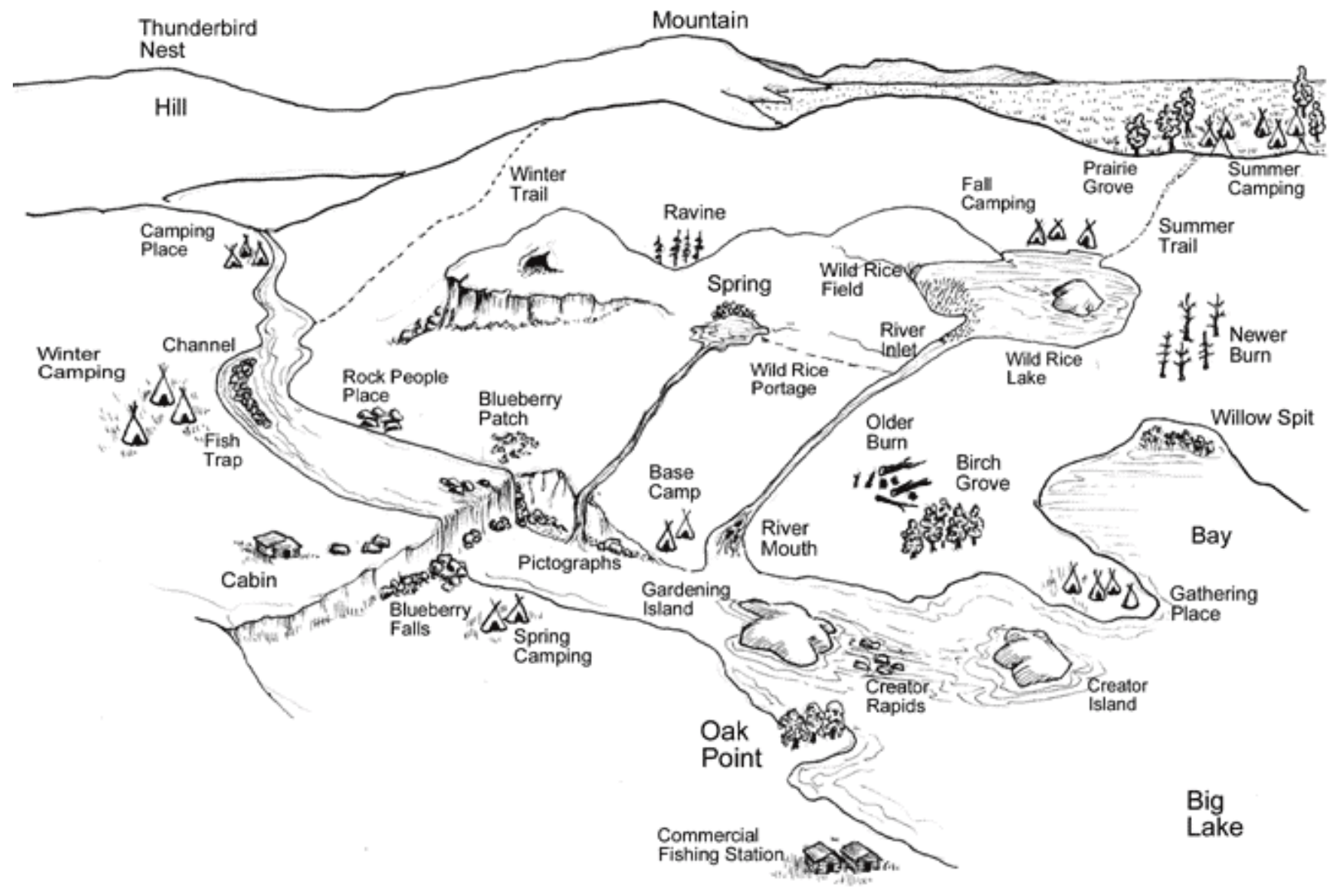

The fur trade emerged in northwestern Ontario in the $17^{\text {th }}$ century and led to a number of novel opportunities for Canada's First Peoples. Often these new opportunities were based upon resources and practices that existed before the fur trade but which required an intensification of production. One such product was sugar made from the sap of maples (Acer saccharum and Acer negundo) and birch (Betula papyrifera). The sugar was used to sweeten the pemmican made from dried blueberries (Vaccinium spp.) and dried buffalo (Bison bison) meat. As a "sugaring bush" did not exist on Shoal Lake, ancestors of current Iskatewizaagegan families transplanted Acer negundo to an island on the lake. Before this time, they would travel to what has become southwest Manitoba to produce sugar for their own use. By transplanting the trees, they were able to create a sugar bush on Shoal Lake near to where they practiced other livelihood activities. This also allowed the families of Iskatewizaagegan to control and intensify production of sugar for trade. The movement of the sugar bush to a place where it did not previously occur required knowledge of the biophysical conditions under which Acer negundo would thrive in a new environment. This sugar bush, although not currently used, still exists on an island of Shoal Lake.

Another important plant that has been traded since before the written historical record to the present is Manomin (Zizania aquatica). Also called wild rice, this plant was propagated and traded extensively by Anishinaabe people throughout northwestern Ontario (Vennum 1988). However, at the turn of the century, the wild rice of many lakes and rivers was destroyed by the construction of dams. This occurred on Shoal Lake and Lake of the Woods when dams were constructed in the early 1900s at the outlet of Lake of the Woods. Dams resulted in a rise in water level, but more damning for wild rice was the reversal of the 
natural water cycle. Prior to damming, the water level would rise in the spring and drop gradually throughout the summer. After damming, the water level would begin to drop in mid-summer but then would be allowed to rise to provide storage for winter power needs. Wild rice is a determinate plant. It stops growing when day length begins to shorten and the "floating leaf" emerges. The floating leaf is critical as it continues photosynthesis during seed fill. When the water level rises in July and August, the floating leaf is submerged, the plant is drowned and the harvest of rice is not possible.

In order to transplant wild rice it is necessary to find a lake that has the right type of soil on the bottom and the right depth of water in the spring and fall (Vennum 1988). Wild rice will only grow in lakes with a "muck" bottom and a specified range of water depth and clarity. The seed requires light of a specific range of wavelength to begin germination. Depth and clarity of water affect the wavelength range that will reach the seed. Shoal Lake families sought out lakes in Manitoba that were not connected to the flooded water systems and had the right characteristics. These lakes produced wild rice throughout the first half of the 1900s. However, in the mid 1900s a provincial park was established and Shoal Lake people were no longer permitted to harvest wild rice in the park.

Shoal Lake people decided at this time to look for a lake near the newly established reserve. Crowduck Lake, just to the north of Shoal Lake, was underlain by the right type of soil and had a "muck" bottom. However, it did not have the right water depth. Walter Redsky, who was the Chief at the time, convinced the Ontario Ministry of Natural Resources to blast a channel through the rock at the outlet of the lake. With the drop in water level, this lake became the most productive manomin lake for Shoal Lake people. During the 1960s, 1970s, and 1980s, this lake was also the main source of commercial rice harvest by Shoal Lake people.

In the examples provided above, the Anishinaabe adapted to changes in an environment that was made up of the interactions between biophysical, social, and cultural structures and processes. Adaptive learning is not just about people adapting in response to the natural processes of a landscape. This changes the emphasis on learning from point-to-point relationships to one in which learning emerges from subjects who are part of a complex network of dynamic relationships.

\section{DISCUSSION: INSTITUTIONS OF KNOWLEDGE}

Anishinaabe elder Walter Redsky's father grew up "on the land." In the middle of winter, Walter related, his father could travel to a place, thrust his hand through the snow and pull up the exact root he needed for a medicine. At any time of year, his father knew exactly where animals, plants, and fish would be located. Things changed during the year and from year to year, but Walter believed that his father knew where animals and plants were, as he was always traveling on the land, undertaking ceremonies, and ensuring the survival of his family. This was Walter's way of saying that he did not need to know that sage, for example, grew on a certain type of rock face. Sure, he could describe the rock face and other landscape categories; however, his father taught Walter that the land is not a stranger of abstract categories. Land is known intimately through experience and journeying. Each place is unique, as an aspect of creation, biophysical characteristics, names, and histories. These teachings by Walter and other Anishinaabe elders tell us something about adaptive learning and social-ecological resilience.

When we began this research, we thought that ecological perception might emerge from taxonomies of biophysical elements, along with their spatial and temporal relationships. The work with the elders, however, also brought out the social and cultural axes of perception. When environments are perceived as social-ecological systems, rules can then evolve out of the dynamics of linked biophysical and cultural environments. The Anishinaabe notion of "land" is closer to the scientific concept of "ecosystem," except that it is an ecosystem that explicitly includes people, their culture, and history (Berkes et al. 1998).

We started this paper by posing several questions that emerge out of the recent resilience literature (Walker et al. 2002, Folke et al. 2003): What processes allow social memory to become dynamic, in tune with ecosystem dynamics? How are individual creativity, social memory, and institutions linked? How does learning lead to building adaptive capacity for socialecological system resilience?

The research reported in this paper indicates that institutions of knowledge are the key characteristic of adaptive learning. Anishinaabe elders have a sophisticated vocabulary to describe the spatial and temporal dynamics of the land. There is a rich 
perception of spatial and temporal dynamics, cognitive knowledge of dynamics, and a social memory of the dynamics. However, the elders insisted that knowledge of the land emerges, not solely from knowledge of biophysical landscapes, but out of experience on the land. This insight led to the formulation of an adaptive learning model that requires a consideration of institutions of knowledge.

Institutions of knowledge, as they emerge from the Anishinaabe case, comprise rules and values about how the process of adaptive learning may occur; the culturally correct way in which memories can be transmitted from one individual to another; the way in which an individual develops his or her own competency; and how individual creativity may lead to authoritative and legitimate knowledge.

Adaptive learning does not occur in the abstract. It emerges through individual action situated in a socialecological environment. A person does not learn a classification of habitats in the abstract, but learns about habitats through experiences on the land. Places on the land are not just described as a category of habitat, but as a place with attributes of biophysical characteristics and history. These places become known as a person travels within the land. Or, as the Cree people of James Bay put it, as "the land gets to know a person" (Berkes, unpublished field notes). It is through journeying along the paths of travel, and encountering the places of memory, that memories are transmitted and new ones created.

People develop their own competencies as they become more familiar with the land, its biophysical characteristics, its temporal and spatial dynamics, and its ceremonies and history. This is lifelong learning, and usually requires many years (Ohmagari and Berkes 1997). However, some middle-aged people may be considered elders if they have developed their competencies relatively quickly. Not all old people are elders; elder is a social role and designation. The basis of authoritative and legitimate social memories emerges from the experience of journeying on the land. Whether the community considers a person knowledgeable is one measure of the person's legitimacy and competency. No doubt that the criteria for legitimacy varies with culture. There may be cultures in which legitimacy and competency as an environmental expert are based, not on experience on the land, but on published papers about the land!

Social memory includes the institution of knowledge, which frames individual remembering, creativity, and learning within a social-ecological environment, the land. Social memory, as discussed in the literature (McIntosh 2000, Folke et al. 2003), includes both the institutions that frame remembering, creativity, and learning, and the palette of perceptions, memories, cognitive knowledge, and technologies that can be drawn upon in relation to remembering, creativity, and learning. The rules-in-use in a culture, or the institutions of knowledge, allow authoritative and legitimate knowledge to be built through experience within a social-ecological system. In the Anishinaabe case, experience on the land is the basis of authority and legitimacy.

What processes make memory dynamic, in tune with ecosystem dynamics? According to the adaptive learning model that we describe in this paper, memory includes perception, cognitive knowledge, technology, institutions, and worldview. In the process of living their daily lives, people draw upon memory. In the case of the Anishinaabe, social memory is based on the life on the land and the spatial and temporal changes observed. Changes in the social-ecological environment lead to remembering, creativity, and learning. As these activities are based in individual experience on the land, they can lead to changes in social memory. As the elders point out, social memory and traditional knowledge can and do change.

It is this adaptive capacity to learn and change that allows for long-term survival, and confers resilience on the social-ecological system. As one reviewer put it, "the ultimate question...is how well institutions of knowledge perform ...in providing societies with the capacity to respond appropriately to environmental change, [and] adapt and persist through time." Institutions of knowledge do not exist in isolation of larger scale drivers. As illustrated by the story of wild rice, the performance of institutions of knowledge is not only dependent on internal processes but is also contingent upon external influences.

In contrast, the loss or abandonment of rules for constructing and transmitting knowledge, and for authority and legitimacy (i.e., the institution of knowledge), would indicate a loss of resilience. More commonly, one refers to social pathologies in a society that is experiencing a breakdown of rules or institutions. The point, however, is that the loss of resilience is not only social, but rather socialecological in nature, because of the coupling between people and the environment in which they live (Levin 1999). 
Adaptive learning for social-ecological resilience, as suggested by this research, requires maintaining the web of relationships of people and places. Such a relationship is captured only partly by the term "cultural landscape." The problem with the term, as it is usually used, is that it does not capture the dynamic interplay between people and land (Ingold 2000). Adaptive learning and resilience are processes by which cultural landscapes become dynamic. Authors such as Butz (1996), Butz and Eyles (1997) and Nabhan (1997) have also tried to capture the two-way relationship between people and landscapes. Such relationships allow social memory to frame creativity, while allowing knowledge to evolve in the face of change. Social memory does not actually evolve directly out of ecosystem dynamics. Rather, social memory both frames creativity within, and emerges from, a dynamic social-ecological environment.

Responses to this article can be read online at: http://www.consecol.org/vol8/iss 1/art5/responses/index.html

\section{Acknowledgments:}

We could not have completed this research without the assistance of the Shoal Lake Resource Institute of Iskatewizaagegan \#39 Independent First Nation (IIFN): Edward Mandamin, Phyllis Jack, Brennan Wapioke, the Chief of IIFN John Wapioke, and Councillors Randy Paishk, Dennis Hunter, Susan Adams, and Laverna Green. We acknowledge Ontario Ministry of Natural Resources personnel: Colin Bowling, Ian Pyke, Peter Schaffer, Gerry Simmons, Peter Uhlig, and Bob White; Luc Duchesne of the Canadian Forest Service, and John Zasada of the USDA Forest Service. Kheryn Klubnikin organized a panel at the 2002 ESA/SER meetings in Tucson that provided us with preliminary feedback on our ideas. Three anonymous reviewers provided insightful and challenging comments that allowed us to greatly improve this paper. Financial support was provided by the Sustainable Forest Management Network (SFMN) and by the Social Sciences and Humanities Research Council (SSHRC) through a grant to F. Berkes and a Doctoral Fellowship to I. DavidsonHunt.

\section{APPENDIX 1. Anishinaabe Ethnoecology: a Sample of Landscape Terminology}

\section{Biogeophysical and cultural terms with English glosses}

Landform/Habitat Terms

English Gloss

Atiinaag

Babiikwaakwaa

Babiikwaakwaag

Biboonishiiwinan

Biinjiboonaagan

Binesiiwassiswun

Daawaapakinigay

Giinaywemitigomiizhikaag

Giinaywewigwasikaag

Giinaywe - point

ikaag - place

Giinaywe - any tree - ikaag

Giishkaapiikaang

Kaang - rocky place
Hill

Patch of trees in open prairie

Place of patch of trees in open prairie

Winter camping

Fish trap

Thunderbird nest

Channel

Oak point

Birch point

Any tree point

Cracks in rock wall - sage location 
Piikaang - rocky area

Giishkaa - rock cracks

Gaagiidazhigiishkaakweyaag

Gitigaan

Gitigaan Minis

Iskite

Iskaate

Iskaate Minis

Ishkwaakite

Kaaobiigiishkensikaag

Kaaobii - narrows

Giishkens - small cedars

Kaaobiikwaang

(Kiiobwakwaag)

Kaazhimaanominikaag

Koochichiing

Kwaa

Maazinaapakinigun

Mamawiitaawin

Manitoo Minis

Manitoo Minis

Mataabiiyaakwaa

Mataabiiyaakwaag

Mitaawang

Mitaawangotina

Mashkiig

Mataabiiyaapkaang

Memengwayshiiwug

Miikana

Miiniikaa

Oteiminaniikaa

Berry '-minaniikaa'

Minis

Minisinaakwaa

Minisinaakwaang

Mitig(-oog)

Mookichiiwanibiik

Neyaa
'Clearcut' - place where it was cut

Garden

Garden Island

To burn

Burnt

Burnt Island

Burnt trees

- just recently burnt where trees still standing

Narrows

- narrows between two points with cedar

Narrows with trees on points

Maanomin field

River inlet

Grove of trees

- used within word construction to refer to a bunch or clump of trees

Pictograph

Multiple family dwelling place / village

Spirit island

Spirit falls / rapids

Shrubby area at edge of water

Place where there are shrubs at edge of water

Sand

Sand ridge

Muskeg

Rocky slope going down to lake

Little rock people place

Trail

Blueberry patch

Strawberry patch

Any berry patch

Island

Island of trees

- refers to a clump of trees found within a swamp

Place of island of trees

Tree(s)

Spring

Point 


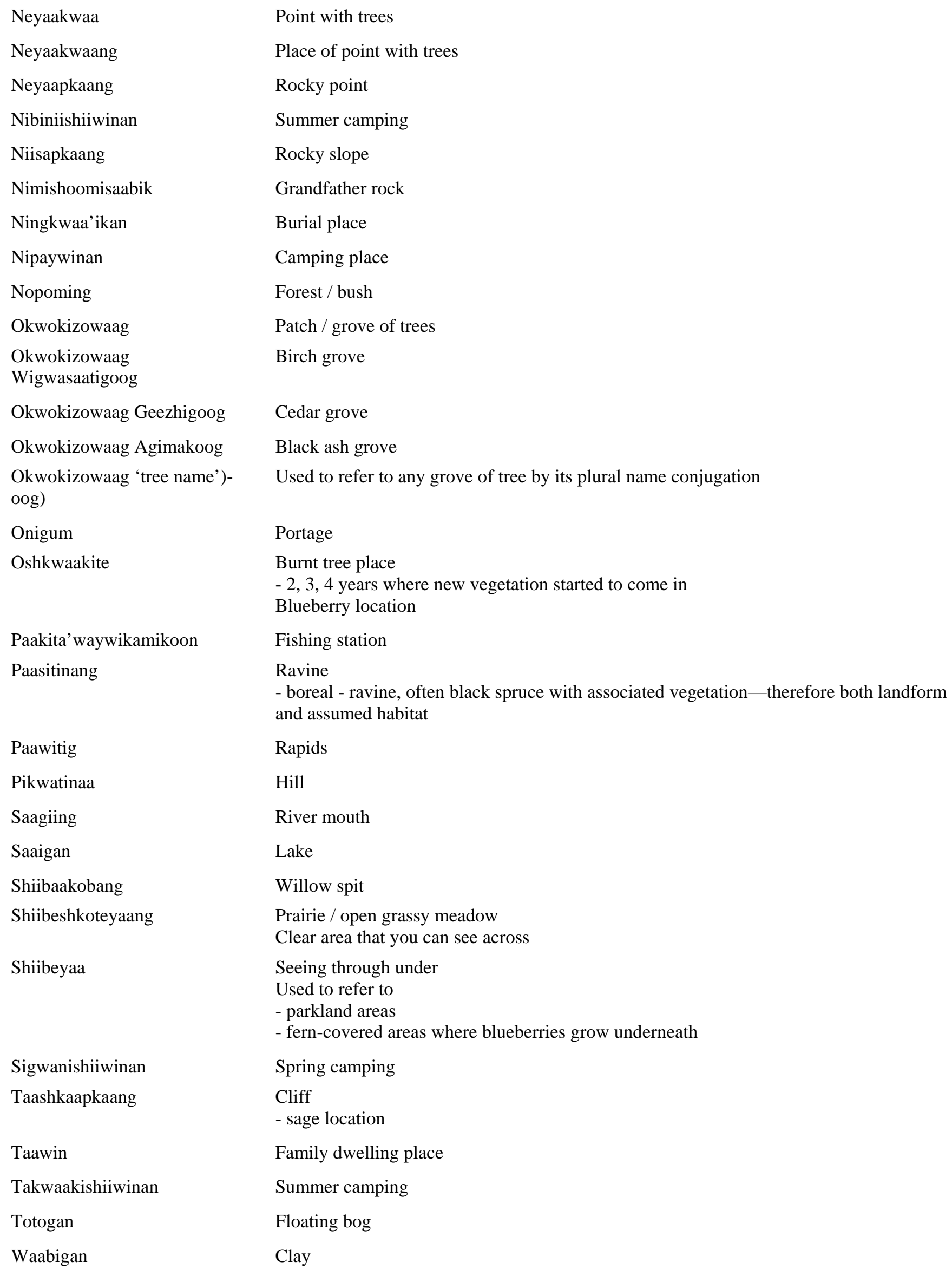




$\begin{array}{ll}\text { Waabiganikaa } & \text { Place of clay } \\ \text { Waachiew } & \text { Big hill / mountain } \\ \text { Waakaa'igan } & \text { Cabin } \\ \text { Wiikwechiishkiiwagaang } & \begin{array}{l}\text { Shallow, muddy bay } \\ \text { - wild rice location }\end{array} \\ \text { Wiikweshkosewaagaang } & \text { Grassy bay } \\ \text { Wiikweyaang } & \text { Bay } \\ \text { Zhiibaaminis } & \text { Narrows between two islands } \\ \text { Zhiibaaminisiing } & \text { Narrows between a group of island } \\ & \text { - often found in front of a bay } \\ \text { Kaazhiibaaminisiwong } & \text { Kaa = Go } \\ & \text { - wong - place where } \\ \text { Go to the place where there are narrows between the islands } \\ \text { Ziibi }\end{array}$

\section{LITERATURE CITED}

Berkes, F. 1999. Sacred Ecology: Traditional Ecological Knowledge and Resource Management. Taylor \& Francis, Philadelphia, Pennsylvania, USA and London, UK.

Berkes, F., J. Colding, and C. Folke, editors. 2003. Navigating Social-ecological Systems: Building Resilience for Complexity and Change. Cambridge University Press, Cambridge, UK.

Berkes, F., P. J. George, R. J. Preston, J. Turner, and B. D. Cummins. 1994. Wildlife harvesting and sustainable regional native economy in the Hudson and James Bay lowland, Ontario. Arctic 47: 350-360.

Berkes, F., M. Kislalioglu, C. Folke, and M. Gadgil. 1998. Exploring the basic ecological unit: ecosystem-like concepts in traditional societies. Ecosystems 1: 409-415.

Berlin, B. 1992. Ethnobiological Classification: Principles of Categorization of Plants and Animals in Traditional Societies. Princeton University Press, Princeton, New Jersey, USA.

Borofsky, R. 1987. Making History: Pukapukan and Anthropological Constructions of Knowledge. Cambridge University Press, Cambridge, UK.

Butz, D. 1996. Sustaining indigenous communities: symbolic and instrumental dimensions of pastoral resource use in Shimshal, northern Pakistan. The Canadian Geographer 40: 36-53.

Butz, D., and J. Eyles. 1997. Reconceptualising senses of place: social relations, ideology and ecology. Geografiska
Annaler, Series B 79: 1-25.

Davidson-Hunt, I. J. 2003. Journeys, Plants and Dreams: Adaptive Learning and Social-Ecological Resilience. Unpublished Dissertation, University of Manitoba, Winnipeg, Manitoba, Canada.

Davidson-Hunt, I. J., and F. Berkes. 2003. Nature and society through the lens of resilience: toward a human-inecosystem perspective. Pages 53-82 in F. Berkes, J. Colding, and C. Folke, editors. Navigating Social-ecological Systems: Building Resilience for Complexity and Change. Cambridge University Press, Cambridge, UK.

Folke, C., S. Carpenter, T. Elmqvist, L. Gunderson, C. S. Holling, B. Walker, J. Bengtsson, F. Berkes, J. Colding, K. Danell, M. Falkenmark, L. Gordon, R. Kasperson, W. Kautsky, A. Kinzig, S. Levin, K.-G. Mäler, F. Moberg, L. Ohlsson, P. Olsson, E. Ostrom, W. Reid, J. Rockström, H. Savenije, and U. Svedin. 2002. Resilience and Sustainable Development: Building Adaptive Capacity in a World of Transformations. International Council for Science, ICSU Series on Science for Sustainable Development No. 3. [Online] URL: http://www.sou.gov.se/mvb/pdf/resiliens.pdf

Folke, C., J. Colding, and F. Berkes. 2003. Synthesis: building resilience and adaptive capacity in socialecological systems. Pages 352-387 in F. Berkes, J. Colding, and C. Folke, editors. Navigating Social-ecological Systems: Building Resilience for Complexity and Change. Cambridge University Press, Cambridge, UK.

Gunderson, L., and C. S. Holling, editors. 2002. Panarchy. Understanding Transformations in Human and Natural Systems. Island Press, Washington, D.C., USA. 
Ingold, T. 2000. The Perception of the Environment: Essays on Livelihood, Dwelling and Skill. Routledge Press, London, UK.

Lee, K. 1993. Compass and Gyroscope. Integrating Science and Politics for the Environment. Island Press, Washington, D.C., USA.

Levin, S. 1999. Fragile Dominion: Complexity and the Commons. Perseus Publishing, Reading, Massachussetts, USA.

McIntosh, R. J. 2000. Climate, history and human action. Pages 1-42 in R. J. McIntosh, J. A. Tainter, and S. K. McIntosh, editors. The Way the Wind Blows: Climate, History and Human Action. Columbia University Press, New York, New York, USA.

McIntosh, R. J., J. A. Tainter, and S. K. McIntosh, editors. 2000. The Way the Wind Blows: Climate, History and Human Action. Columbia University Press, New York, New York, USA.

Nabhan, G. P. 1997. Cultures of Habitat: On Nature, Culture, and Story. Cunterpoint Press, Washington, D.C., USA.

Ohmagari, K., and F. Berkes. 1997. Transmission of indigenous knowledge and bush skills among the Western James Bay Cree women of subarctic Canada. Human Ecology 25:197-222.

Ontario Ministry of Natural Resources. 1996. Terrestrial and Wetland Ecosites of Northwestern Ontario. NWST Field Guide FG-02. Ontario Ministry of Natural Resources, Thunder Bay, Ontario, Canada.

Ostrom, E. 1990. Governing the Commons: the Evolution of Institutions for Collective Actions. Cambridge University Press, Cambridge, UK.

Ruta, T. 2002. Forest Patches and Non-timber Forest Products in the Boreal Forest: a Case Study from the Shoal Lake Watershed, Northwestern Ontario. Unpublished thesis, University of Manitoba, Winnipeg, Manitoba, Canada.

Sims, R. A., W. D. Towill, K. A. Baldwin, and G. M. Wickware. 1989. Field Guide to the Forest Ecosystem Classification for Northwestern Ontario. Ontario Ministry of Natural Resources, Thunder Bay, Ontario, Canada.

Vennum, T. Jr. 1988. Wild Rice and the Ojibway People. Minnesota Historical Society, St. Paul, Minnesota, USA.

Walker, B, S. Carpenter, J. Anderies, N. Abel, G. Cumming, M. Janssen, L. Lebel, J. Norberg, G. Peterson, and R. Pritchard. 2002. Resilience management in social-ecological systems: a working hypothesis for a participatory approach. Conservation Ecology 6(1): 14. [Online] URL: www.consecol.org/vol6/iss1/art14.

Westley, F. 2002. The devil in the dynamics: adaptive management on the front lines. Pages 333-360 in L. Gunderson and C. S. Holling, editors. Panarchy. Understanding Transformations in Human and Natural Systems. Island Press, Washington, D.C., USA. 